\title{
The histone methyltransferase EZH2 promotes mammary stem and luminal progenitor cell expansion, metastasis and inhibits estrogen receptor-positive cellular differentiation in a model of basal breast cancer
}

\author{
JIANCHUN WU and DAVID L. CROWE \\ University of Illinois Cancer Center, Chicago, IL 60612, USA
}

Received April 8, 2015; Accepted April 29, 2015

DOI: $10.3892 /$ or.2015.4003

\begin{abstract}
Mammary stem cells (MSCs) are the progenitor population for human breast epithelia. MSCs give rise during mammary gland development to estrogen receptor (ER)-negative basal cells and the ER luminal progenitor (LP) population which maintains $\mathrm{ER}^{+}$and $\mathrm{ER}^{-}$luminal cells. The MSC population is expanded and tumorigenic in some mouse mammary cancer models, and these tumor-initiating cells have been isolated from human breast cancers. MSC expansion is associated with aggressive biological behavior in human breast cancer. The LP population is tumorigenic in some mouse mammary cancer models, and is the progenitor population of basal breast cancer in humans. The enhancer of zeste homolog 2 (EZH2) is a methyltransferase which catalyzes lysine 27 methylation in histone $\mathrm{H} 3$ resulting in suppression of target gene expression. The histone demethylase JMJD3 opposes the activity of EZH2 by demethylating histone $\mathrm{H} 3$ lysine $27 . \mathrm{EZH} 2$ is a member of the polycomb group of proteins which regulates cell type identity. EZH2 expression was found to be increased in histologically normal human breast tissue among women with high breast cancer risk, and was elevated in ductal hyperplasia and ductal carcinoma in situ. EZH2 overexpression is associated with poorly differentiated and aggressive breast cancer in humans. However, the mechanisms by which EZH2 results in increased breast cancer risk and aggressive tumors are not completely characterized. Using in vivo transplantation of mammary cancer stem cells transduced with EZH2 or JMJD3 shRNAs, we demonstrated that $\mathrm{EZH} 2$ promotes mammary stem and LP cell expansion, metastasis and inhibits ER-positive cellular differentiation.
\end{abstract}

Correspondence to: Professor David L. Crowe, University of Illinois Cancer Center, 801 S. Paulina Street, Chicago, IL 60612, USA

E-mail: dlcrowe@uic.edu

Key words: EZH2, JMJD3, cancer stem cells, protein methylation, gene expression, intercellular signaling

\section{Introduction}

Breast cancer accounts for $25 \%$ of all cancers in women worldwide. In the US 296,000 women were diagnosed with breast cancer and over 39,000 died of the disease in 2013 (1). Numerous treated breast cancer patients will develop incurable metastatic disease, with a median survival of 3 years. Standard adjuvant therapies have a small impact on breast cancer survival, yet more than $\$ 16$ billion were spent on breast cancer clinical care in 2010 (2). Most breast cancer risk factors cannot be modified, and include age, family and reproductive history, BRCA1 status and breast density.

Mammary stem cells (MSCs) are the progenitor population for human breast epithelia (3-5). MSCs give rise during mammary gland development to estrogen receptor (ER)-negative basal cells and the ER- luminal progenitor (LP) population which maintains $\mathrm{ER}^{+}$and $\mathrm{ER}^{-}$luminal cells (6-8). MSCs have been isolated from humans and mice using cell surface markers (9-11). The MSC population is expanded and tumorigenic in some mouse mammary cancer models $(12,13)$, and these tumor-initiating cells have been isolated from human breast cancers (14-18). MSC expansion is associated with aggressive biological behavior in human breast cancer $(19,20)$. The LP population is tumorigenic in some mouse mammary cancer models (21), and is the progenitor population of basal breast cancer in humans (22).

The enhancer of zeste homolog 2 (EZH2) is a methyltransferase which catalyzes methylation of lysine 27 in histone $\mathrm{H} 3$ resulting in suppression of target gene expression (23). The histone demethylase JMJD3 opposes the activity of EZH2 by demethylating histone $\mathrm{H} 3$ lysine 27. $\mathrm{EZH} 2$ is a member of the polycomb group of proteins which regulates cell type identity (24). EZH2 overexpression in the mouse mammary gland was found to produce intraductal hyperplasia and to delay involution. EZH2 expression was increased in histologically normal human breast tissue among women at high breast cancer risk (25), and was elevated in ductal hyperplasia and ductal carcinoma in situ (26). EZH2 overexpression is associated with poorly differentiated and aggressive breast cancer in humans $(27,28)$. However, the mechanisms by which EZH2 results in increased breast cancer risk and aggressive tumors are not completely characterized. 
Using in vivo transplantation of mammary cancer stem cells transduced with EZH2 or JMJD3 shRNAs, we demonstrated that EZH2 promotes mammary stem and LP cell expansion, metastasis and inhibits ER-positive cellular differentiation.

\section{Materials and methods}

Mouse breeding and procedures. We bred MMTV-Wnt1 mice obtained from The Jackson Laboratories (Bar Harbor, ME, USA). Mammary tumorigenesis is driven by Wnt1 oncogene expression which is a model of basal subtype breast cancer. All mice were genotyped using PCR amplification of extracted tail DNA according to The Jackson Laboratories protocols. Twenty tumors were obtained for analysis. Tumors were trypsin dissociated for cryopreservation in liquid nitrogen.

Fluorescence-activated cell sorting. Dissociated tumor cells were incubated with phycoerythrin-conjugated anti-CD24 and AlexaFluor 488 conjugated anti-CD49f antibodies (Stem Cell Technologies, Vancouver, BC, Canada), washed in phosphate-buffered saline (PBS), and the $\mathrm{CD} 24^{+} / \mathrm{CD} 49^{\text {fhi }}$ MSC fraction was sorted by flow cytometry (MoFlo Astrios, Becton Dickinson, Franklin Lakes, NJ). The CD $24^{+} / \mathrm{CD} 49^{\text {flo }} / \mathrm{CD} 1^{+}$ LP fractions were sorted in separate experiments. Dissociated tumor cells were incubated with fluorescein-conjugated estradiol to identify ER-positive cells prior to sorting.

Cell culture, lentiviral transduction and transplantation. Sorted MSCs $\left(10^{4}\right)$ from MMTV-Wnt1 tumors were cultured in 3:1 Dulbecco's modified Eagle's medium:F12 medium containing 1X B27 supplement, $10 \mathrm{ng} / \mathrm{ml}$ epidermal growth factor, $25 \mathrm{ng} / \mathrm{ml}$ basic fibroblast growth factor, $0.2 \%$ heparin, $40 \mu \mathrm{g} / \mathrm{ml}$ gentamicin, $2.5 \mu \mathrm{g} / \mathrm{ml}$ amphotericin B (MSC medium) at $37^{\circ} \mathrm{C}$ in a humidified atmosphere of $5 \% \mathrm{CO}_{2}$ and separately transduced with lentiviruses containing control, EZH2 or JMJD3 shRNAs with $5 \mu \mathrm{g} / \mathrm{ml}$ Polybrene overnight according to the manufacturer's protocol (Thermo Scientific, Waltham, MA, USA) at $37^{\circ} \mathrm{C}$ in a humidified atmosphere of $5 \% \mathrm{CO}_{2}$. MSC medium was replaced and cells were cultured for $24 \mathrm{~h}$. Puromycin $(2 \mu \mathrm{g} / \mathrm{ml})$ was added and the cells were incubated for $48 \mathrm{~h}$. MSC medium was replaced and the cells were injected into the fat pads of 2-month-old immunocompromised NU/J mice. In separate experiments, fat pads were transplanted with $10^{4}$ sorted MSCs with either $\mathrm{ER}^{+}$or ER- luminal cells from the MMTV-Wnt1 mammary tumors. Mice were examined weekly for tumor formation for up to 6 months. The latency and volume of tumors were recorded for each mouse. Complete necropsy was performed on each mouse. Portions of each tumor were fixed in $10 \%$ formalin, flash frozen for storage at $-80^{\circ} \mathrm{C}$ and trypsin dissociated for cryopreservation in liquid nitrogen.

$q R T-P C R$. RNA was extracted from sorted MSCs and reverse transcribed according to the manufacturer's instructions (Invitrogen, Carlsbad, CA, USA). PCR reactions without cDNA template were used as the negative control. cDNA was amplified using EZH2, JMJD3 and $\beta$-actin primers. PCR was performed using thermal cycling parameters of $94^{\circ} \mathrm{C}$ for $25 \mathrm{sec}, 55^{\circ} \mathrm{C}$ for $1 \mathrm{~min}$ and $72^{\circ} \mathrm{C}$ for $1 \mathrm{~min}$ (Stratagene, La Jolla, CA, USA) with SYBR-Green.

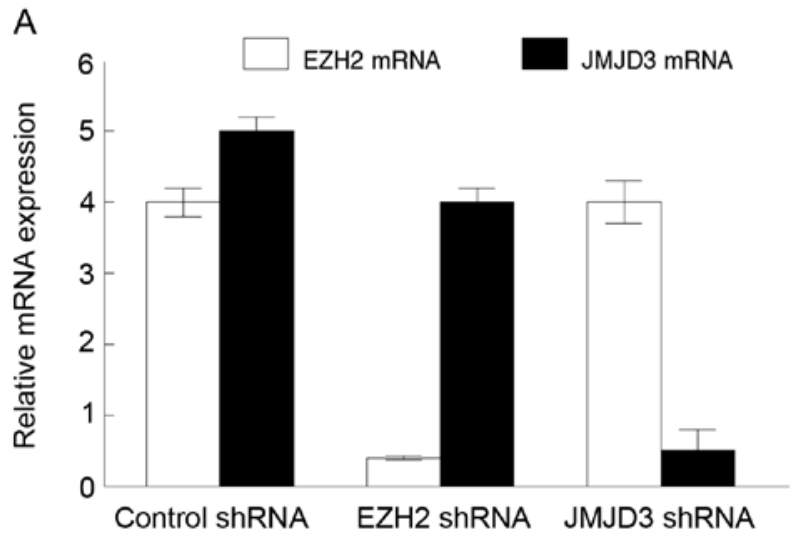

B

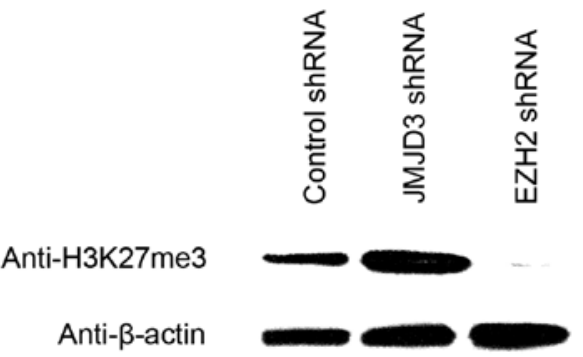

Figure 1. EZH2 and JMJD3 regulate histone H3 methylation in mammary cancer stem cells. EZH2, JMJD3 and control shRNAs were transduced into mammary cancer stem cells from MMTV-Wnt1 tumors and transplanted into cleared mammary fat pads of immunodeficient mice. (A) EZH2 and JMJD3 mRNA levels were determined in the transplanted tumors by qRTPCR. Error bars indicate standard error measurement. (B) Levels of lysine 27 trimethylation of histone $\mathrm{H} 3$ (H3K27me3) in each group were determined by western blotting. $\beta$-actin expression was used as the control for equal loading in each lane. Experiments were performed in triplicate and representative blots are shown. EZH2, enhancer of zeste homolog 2 .

Western blotting. Sorted MSCs from MMTV-Wnt1 tumors were lysed in 1X Laemmli buffer. Fifty micrograms of total cellular proteins was separated by SDS-PAGE. Proteins were electroblotted to PVDF membranes (Roche Applied Sciences, Indianapolis, IN, USA). Blots were incubated with blocking solution followed by anti-histone H3K27me 3 and anti- $\beta$-actin antibodies for $16 \mathrm{~h}$ at $4^{\circ} \mathrm{C}$. After washing in Tris-buffered saline containing $0.1 \%$ Tween-20, blots were incubated for $30 \mathrm{~min}$ at room temperature with an anti-IgG secondary antibody conjugated to horseradish peroxidase. Bands were visualized by the enhanced chemiluminescence method and quantitated by densitometry. Data were analyzed by t-test.

Histopathology and immunohistochemistry. Formalin-fixed tumor tissue was dehydrated in ethanol, cleared in xylene and embedded in paraffin. Sections were deparaffinized and stained with hematoxylin and eosin. For immunohistochemical studies, the sections were rehydrated in PBS (pH 7.4) and blocked with $10 \%$ normal serum. For immunohistochemistry studies, the sections were incubated with PCNA primary antibody overnight at room temperature. Following washing in PBS, the sections were incubated with biotinylated secondary antibody and streptavidin-conjugated horseradish peroxidase. Antigen-antibody complexes were detected by incubation with peroxide substrate solution containing aminoethylcarbazole chromogen followed by hematoxylin counterstaining. The 

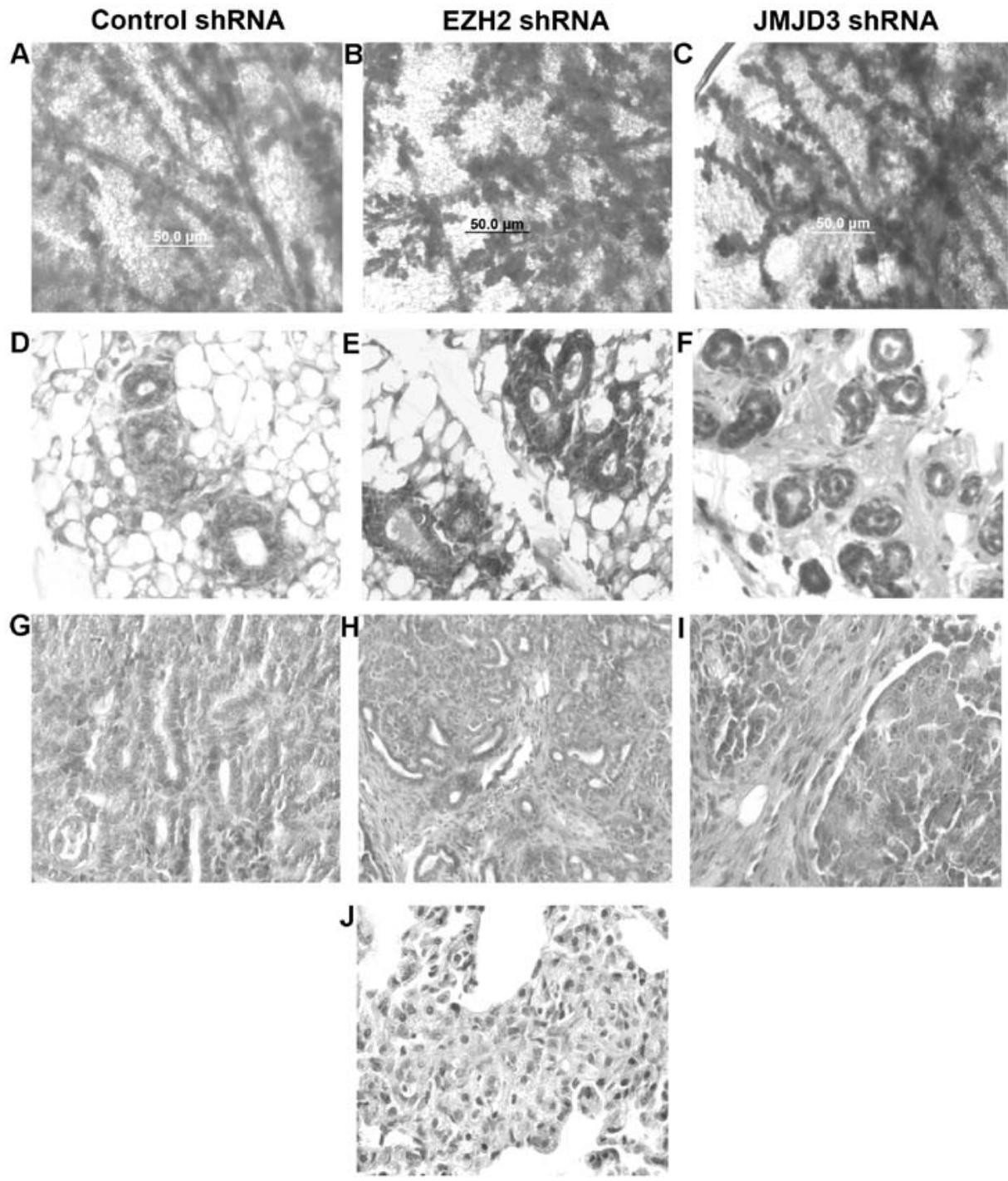

Figure 2. Increased EZH2 activity promotes lung metastasis in the MMTV-Wnt1 model of mammary cancer. (A-C) Whole mount preparations of cleared mammary fat pads transplanted with mammary cancer stem cells transduced with the control, EZH2 or JMJD3 shRNAs. (D-F) H\&E staining of histopathologic sections of cleared mammary fat pads transplanted with mammary cancer stem cells transduced with the control, EZH2 or JMJD3 shRNAs. (G-I) H\&E staining of histopathologic sections of mammary tumors derived from transplanted mammary cancer stem cells transduced with the control, EZH2 or JMJD3 shRNAs. (J) H\&E staining of histopathologic sections of lung metastasis from mammary tumors derived from transplanted mammary cancer stem cells transduced with the JMJD3 shRNAs. A minimum of five transplants was performed for each group. Representative sections are shown. EZH2, enhancer of zeste homolog 2; H\&E, hematoxylin and eosin.

percentage of PCNA cells in 10 random high power fields was determined by counting. Data were analyzed by t-test.

Cell death analysis. Tumor tissue sections were incubated with terminal deoxynucleotidyl transferase and dUTP-fluorescein for $1 \mathrm{~h}$ at $37^{\circ} \mathrm{C}$ according to the manufacturer's recommendations (Roche Applied Sciences). After washing, apoptotic cells were visualized by fluorescence microscopy following coverslipping with anti-fade mounting medium containing DAPI. The percentage of fluorescent cells in 10 random high power fields was determined by counting. Data were analyzed by t-test.

\section{Results}

To determine the role of EZH2 in mammary cancer stem cell function, we transduced MSCs from MMTV-Wnt1 mammary tumors with EZH2, JMJD3 or control lentiviral shRNAs. JMJD3 is a histone demethylase which counteracts EZH2 activity by removing methyl groups from lysine 27 of histone H3. EZH2 and JMJD3 shRNAs reduced expression of these mRNAs in the tumorigenic MSCs by $80 \%$ compared to the control shRNAs (Fig. 1A). We examined trimethylation of lysine 27 in histone $\mathrm{H} 3$ in the transduced tumorigenic MSCs by western blotting. JMJD3 inhibition produced a 3 -fold upregulation of $\mathrm{H} 3 \mathrm{~K} 27 \mathrm{me} 3$ levels in the tumorigenic MSCs, while EZH2 shRNAs resulted in $>95 \%$ reduction of H3K27me3 (Fig. 1B). We concluded that EZH2 and JMJD3 regulate histone $\mathrm{H} 3 \mathrm{~K} 27 \mathrm{me} 3$ levels in tumorigenic MSCs.

We transplanted tumorigenic MSCs transduced with control, EZH2 or JMJD3 shRNAs to the cleared fat pads of immunodeficient mice. We examined mammary gland reconstitution by these MSCs using whole mount staining. As shown in Fig. 2A-C, transplanted mammary glands exhibited 

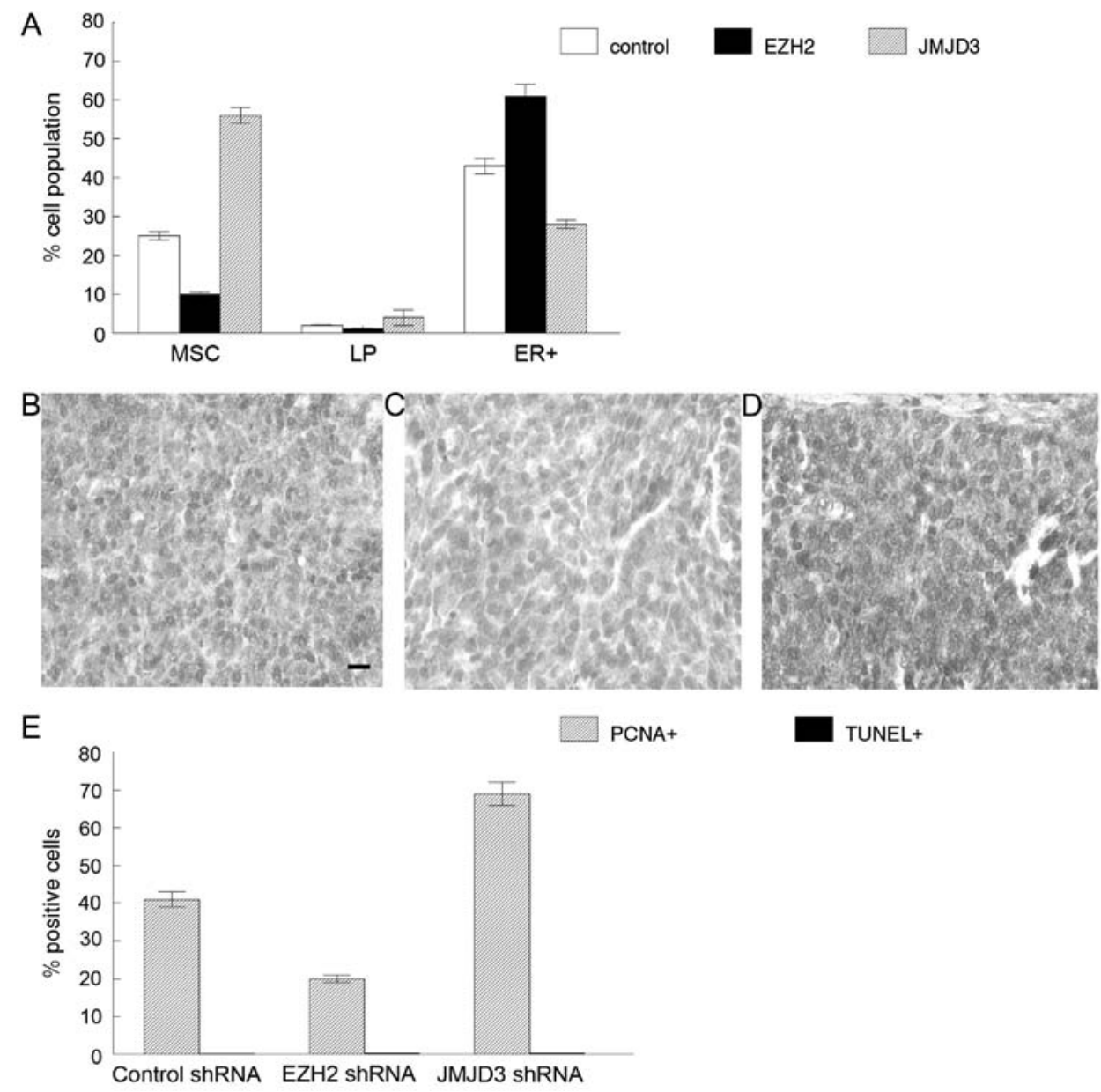

Figure 3. Increased EZH2 activity expands the tumorigenic mammary cancer stem cell and luminal progenitor populations yet inhibits ER ${ }^{+}$differentiation. (A) FACS analysis of mammary tumors derived from cancer stem cells transduced with the control, EZH2 or JMJD3 shRNAs. Mammary stem cell (MSC), luminal progenitor and $\mathrm{ER}^{+}$cell populations were sorted by flow cytometry from mammary tumors in each group. Error bars indicate standard error measurement. Elevated EZH2 activity increases proliferation in the MMTV-Wnt1 mammary tumors. PCNA immunohistochemistry was performed on tumor sections derived from the MSCs transduced with (B) the control, (C) EZH2 or (D) JMJD3 shRNAs. Representative sections are shown. (E) Quantization of PCNA and TUNEL ${ }^{+}$cells in the tumor sections derived from the MSCs transduced with the control, EZH2 and JMJD3 shRNAs. Error bars indicate standard error measurement. EZH2, enhancer of zeste homolog 2; FACS fluorescence-activated cell sorting.

hyperplastic branching characteristic of the MMTV-Wnt1 mice in all three transduced groups. There were no statistically significant differences in the number of branches or terminal end buds between the three groups. We also examined these reconstituted mammary glands by histopathologic sectioning, and hematoxylin and eosin (H\&E) staining. Reconstituted mammary glands exhibited ductal and basal cell hyperplasia characteristic of MMTV-Wnt1 mice (Fig. 2D-F). Some glands exhibited early signs of stromal cell hyperplasia and fibrosis. However, we did not detect significant differences in the histopathology of reconstituted mammary glands transduced with the control, EZH2 nor JMJD3 shRNAs. Mammary glands transplanted with the tumorigenic MSCs transduced with the control,EZH2 or JMJD3 shRNAs developed mammary tumors. We did not detect significant differences in tumor latency or growth rate between the three groups. Tumors from each group were classified as poorly differentiated adenocarcinoma exhibiting ductal and stromal hyperplasia (Fig. 2G-I). Metastatic tumors were not detected in cancers arising from the MSCs transduced with the control or EZH2 shRNAs. However, lung metastasis was detected in all immunodeficient mice bearing tumors derived from the MSCs transduced with the JMJD3 shRNAs. Lung metastases were classified as poorly differentiated adenocarcinoma (Fig. 2J). We concluded that increased EZH2 activity promotes lung metastasis in MMTV-Wnt1 mammary cancer.

To determine whether EZH2 activity alters tumorigenic MSC and LP cell fractions in MMTV-Wnt1 mammary tumors, we sorted these populations by fluorescence-activated cell sorting (FACS) from cancers derived from the MSCs transduced with the control, EZH2 or JMJD3 shRNAs. As shown in Fig. 3A, the MSC fraction in the mammary tumors transduced with the EZH2 shRNAs was reduced by 2.5 -fold $(\mathrm{P}<0.01)$. Similarly the tumorigenic LP fraction in the tumors transduced with the EZH2 shRNAs was reduced by 2 -fold $(\mathrm{P}<0.03)$. However, the $\mathrm{ER}^{+}$luminal cell fraction increased from 42 to $61 \%(\mathrm{P}<0.05)$. We also sorted the tumorigenic MSC and LP cell fractions from tumors derived from the MSCs transduced with JMJD3 shRNAs. The MSC fraction in mammary tumors transduced with JMJD3 shRNAs increased from 25 to $56 \%(\mathrm{P}<0.002)$, and the LP cell fraction also was elevated by 2 -fold $(\mathrm{P}<0.04)$. However the $\mathrm{ER}^{+}$luminal cell fraction was reduced from 42 to $28 \%(\mathrm{P}<0.02)$. We concluded that $\mathrm{EZH} 2$ activity promotes tumorigenic MSC and LP cell 


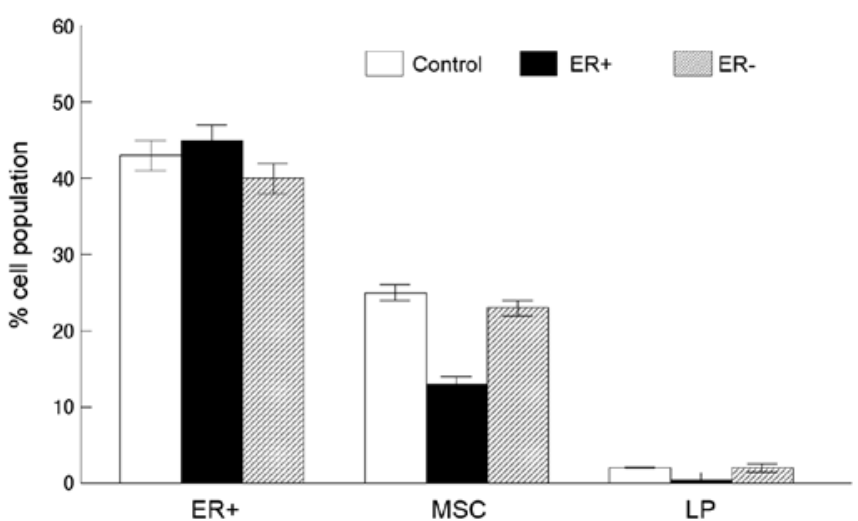

Figure $4 . \mathrm{ER}^{+}$cells inhibit the tumorigenic mammary stem cell and luminal progenitor populations. MSCs were transplanted alone (control) or with $\mathrm{ER}^{+}$ or ER luminal cells from MMTV-Wnt1 mammary tumors to cleared mammary fat pads of immunodeficient mice. Transplanted tumors were sorted by flow cytometry to determine the $\mathrm{ER}^{+}$, MSC and LP fractions. At least five transplants were performed in each group. Error bars indicate standard error measurement. MSCs, mammary stem cells; LP, luminal progenitor.

expansion in mammary tumors yet represses $\mathrm{ER}^{+}$cellular differentiation.

To determine the mechanism of increased MSC and LP cell fractions in these tumors, we examined proliferation and programmed cell death in cancers from each group. The $\mathrm{PCNA}^{+}$cell fraction was reduced in the mammary tumors derived from the MSCs transduced with EZH2 shRNAs compared to the control transplants $(20$ vs. $41 \%$; $\mathrm{P}<0.01$; Fig. 3B, C and E). The $\mathrm{PCNA}^{+}$cell fraction was significantly increased in the mammary tumors derived from the MSCs transduced with the JMJD3 shRNAs compared to the control transplants ( 69 vs. $41 \%$; $\mathrm{P}<0.003$; Fig. 3B, D and E). There were no significant differences in the $\mathrm{TUNEL}^{+}$cell fractions in the mammary tumors derived from the MSCs transduced with the EZH2 or JMJD3 shRNAs compared to the control transplants (Fig. 3E). We concluded that EZH2 promotes tumor cell proliferation in our model of basal mammary cancer.

Our results demonstrated that EZH2 promoted MSC and LP expansion and inhibited $\mathrm{ER}^{+}$cellular differentiation (Fig. 3). To determine whether $\mathrm{ER}^{+}$cells inhibited MSC expansion as a possible mechanism for these observations, we transplanted tumor-derived $\mathrm{ER}^{+}$or ER luminal cells with the MSCs into the cleared mammary fat pads of immunodeficient mice. Tumors resulting from these transplants were sorted by FACS to determine the MSC and LP cell fractions. As shown in Fig. 4, the mammary tumors derived from transplants of the MSCs and $\mathrm{ER}^{+}$cells exhibited significantly reduced MSC fractions compared to those derived from the MSCs transplanted with the ER cells ( 13 vs. $24 \%$; $\mathrm{P}<0.002$ ). Similarly, mammary tumors derived from transplants of the MSCs and $\mathrm{ER}^{+}$cells exhibited significantly reduced LP fractions compared to those derived from the MSCs transplanted with the ER' cells (0.4 vs. $2 \%$; $\mathrm{P}<0.04)$. We conclude that $\mathrm{ER}^{+}$cells inhibit MSC and LP expansion in a model of basal mammary cancer.

\section{Discussion}

EZH2 is associated with younger age at breast cancer diagnosis (29), increased tumor size, high histopathologic grade, negative hormone receptor status, epidermal growth factor receptor and Her 2 overexpression, p53 mutations, lymphatic invasion, poor survival and metastasis (30-32). Our results demonstrated that EZH2 activity was associated with lung metastasis in a model of basal breast cancer. Future studies will determine which of these genetic changes are the direct result of EZH2-mediated regulation of target genes.

Our results demonstrated that EZH2 results in expansion of tumorigenic MSCs and LP cells. Previous studies demonstrated that expansion of breast tumor-initiating cells resulted from Raf1 or Notch gene expression in cancers overexpressing EZH2 $(33,34)$. The present study was the first to determine that EZH2 also induced expansion of the tumorigenic LP population in basal mammary tumors. Our results also demonstrated that EZH2 suppresses ER ${ }^{+}$cellular differentiation. Previous retrospective studies using human breast cancer tissue demonstrated that patients with high tumoral EZH2 expression had the least clinical benefit from anti-estrogen therapy (35). We also demonstrated that EZH 2 activity resulted in increased cell proliferation which was observed in human breast cancers (36). A previous in vitro study demonstrated that EZH2 inhibition resulted in decreased proliferation of human breast cancer cell lines (37). The present study demonstrated a novel mechanism by which tumor-derived $\mathrm{ER}^{+}$cells repress tumorigenic MSC and LP expansion.

EZH2 overexpression was shown to induce ductal hyperplasia in the mouse mammary gland (24). MMTV-Wnt1 mammary glands exhibit ductal hyperplasia (13), and we did not detect changes in glandular hyperplasia resulting from transplantation of the Wnt1 tumor-derived MSCs transduced with the EZH2 or JMJD3 shRNAs. Similarly, mammary tumors derived from these transplants did not exhibit significant differences in histopathologic appearance. These results are likely due to Wnt1-induced hyperplasia which overrides the effects of EZH2.

In summary, EZH2 promotes tumorigenic MSC and LP cell expansion and metastasis while suppressing $\mathrm{ER}^{+}$ cellular differentiation. Future studies will determine how EZH2 induces mammary tumor cell proliferation, expansion of the tumorigenic LP cell population, and suppresses $\mathrm{ER}^{+}$ cellular differentiation.

\section{Acknowledgements}

This study was supported by the Department of Defense Breast Cancer Research Program award W81XWH-10-1-0081.

\section{References}

1. American Cancer Society: Cancer Facts and Figures 2013. American Cancer Society, Inc., Atlanta, 2013.

2. Mariotto AB, Yabroff KR, Shao Y, Feuer EJ and Brown ML: Projections of the cost of cancer care in the United States: 2010-2020. J Natl Cancer Inst 103: 117-128, 2011.

3. Crowe DL, Parsa B and Sinha UK: Relationships between stem cells and cancer stem cells. Histol Histopathol 19: 505-509, 2004.

4. Stingl J, Raouf A, Emerman JT and Eaves CJ: Epithelial progenitors in the normal human mammary gland. J Mammary Gland Biol Neoplasia 10: 49-59, 2005.

5. Visvader JE: Keeping abreast of the mammary epithelial hierarchy and breast tumorigenesis. Genes Dev 23: 2563-2577, 2009.

6. Visvader JE and Lindeman GJ: Mammary stem cells and mammopoiesis. Cancer Res 66: 9798-9801, 2006. 
7. Van Keymeulen A, Rocha AS, Ousset M, Beck B, Bouvencourt G, Rock J, Sharma N, Dekoninck S and Blanpain C: Distinct stem cells contribute to mammary gland development and maintenance. Nature 479: 189-193, 2011.

8. Shehata M, Teschendorff A, Sharp G, Novcic N, Russell IA Avril S, Prater M, Eirew P, Caldas C and Watson CJ: Phenotypic and functional characterisation of the luminal cell hierarchy of the mammary gland. Breast Cancer Res 14: R134, 2012.

9. Dontu G, Abdallah WM, Foley JM, Jackson KW, Clarke MF, Kawamura MJ and Wicha MS: In vitro propagation and transcriptional profiling of human mammary stem/progenitor cells. Genes Dev 17: 1253-1270, 2003.

10. Shackleton M, Vaillant F, Simpson KJ, Stingl J, Smyth GK, Asselin-Labat ML, Wu L, Lindeman GJ and Visvader JE: Generation of a functional mammary gland from a single stem cell. Nature 439: 84-88, 2006.

11. Stingl J, Eirew P, Ricketson I, Shackleton M, Vaillant F, Choi D, Li HI and Eaves CJ: Purification and unique properties of mammary epithelial stem cells. Nature 439: 993-997, 2006.

12. Li Y, Welm B, Podsypanina K, Huang S, Chamorro M, Zhang X, Rowlands T, Egeblad M, Cowin P, Werb Z, et al: Evidence that transgenes encoding components of the Wnt signaling pathway preferentially induce mammary cancers from progenitor cells Proc Natl Acad Sci USA 100: 15853-15858, 2003.

13. Liu BY, McDermott SP, Khwaja SS and Alexander CM: The transforming activity of Wnt effectors correlates with their ability to induce the accumulation of mammary progenitor cells. Proc Natl Acad Sci USA 101: 4158-4163, 2004.

14. Al-Hajj M, Wicha MS, Benito-Hernandez A, Morrison SJ and Clarke MF: Prospective identification of tumorigenic breast cancer cells. Proc Natl Acad Sci USA 100: 3983-3988, 2003.

15. Ponti D, Costa A, Zaffaroni N, Pratesi G, Petrangolini G, Coradini D, Pilotti S, Pierotti MA and Daidone MG: Isolation and in vitro propagation of tumorigenic breast cancer cells with stem/progenitor cell properties. Cancer Res 65: 5506-5511, 2005.

16. Charafe-Jauffret E, Ginestier C, Iovino F, Wicinski J, Cervera N Finetti P, Hur MH, Diebel ME, Monville F, Dutcher J, et al: Breast cancer cell lines contain functional cancer stem cells with metastatic capacity and a distinct molecular signature. Cancer Res 69: 1302-1313, 2009.

17. Han JS and Crowe DL: Tumor initiating cancer stem cells from human breast cancer cell lines. Int J Oncol 34: 1449-1453, 2009.

18. Liu H, Patel MR, Prescher JA, Patsialou A, Qian D, Lin J, Wen S, Chang YF, Bachmann MH, Shimono Y, et al: Cancer stem cells from human breast tumors are involved in spontaneous metastases in orthotopic mouse models. Proc Natl Acad Sci USA 107: 18115-18120, 2010

19. Woodward WA, Chen MS, Behbod F, Alfaro MP, Buchholz TA and Rosen JM: WNT/beta-catenin mediates radiation resistance of mouse mammary progenitor cells. Proc Natl Acad Sci USA 104: 618-623, 2007.

20. Pece S, Tosoni D, Confalonieri S, Mazzarol G, Vecchi M, Ronzoni S, Bernard L, Viale G, Pelicci PG and Di Fiore PP: Biological and molecular heterogeneity of breast cancers correlates with their cancer stem cell content. Cell 140: 62-73, 2010.

21. Vaillant F, Asselin-Labat ML, Shackleton M, Forrest NC, Lindeman GJ and Visvader JE: The mammary progenitor marker CD61/beta3 integrin identifies cancer stem cells in mouse models of mammary tumorigenesis. Cancer Res 68: 7711-7717, 2008.

22. Lim E, Vaillant F, Wu D, Forrest NC, Pal B, Hart AH, AsselinLabat ML, Gyorki DE, Ward T, Partanen A, et al: Aberrant luminal progenitors as the candidate target population for basal tumor development in BRCA1 mutation carriers. Nat Med 15 907-913, 2009

23. Bhan A, Hussain I, Ansari KI, Bobzean SA, Perrotti LI and Mandal SS: Histone methyltransferase EZH2 is transcriptionally induced by estradiol as well as estrogenic endocrine disruptors bisphenol-A and diethylstilbestrol. J Mol Biol 426: 3426-3441, 2014.
24. Li X, Gonzalez ME, Toy K, Filzen T, Merajver SD and Kleer CG: Targeted overexpression of EZH2 in the mammary gland disrupts ductal morphogenesis and causes epithelial hyperplasia. Am J Pathol 175: 1246-1254, 2009.

25. Ding L, Erdmann C, Chinnaiyan AM, Merajver SD and Kleer CG: Identification of EZH2 as a molecular marker for a precancerous state in morphologically normal breast tissues. Cancer Res 66: 4095-4099, 2006.

26. Ding L and Kleer CG: Enhancer of Zeste 2 as a marker of preneoplastic progression in the breast. Cancer Res 66: 9352-9355, 2006.

27. Kleer CG, Cao Q, Varambally S, Shen R, Ota I, Tomlins SA, Ghosh D, Sewalt RG, Otte AP, Hayes DF, et al: EZH2 is a marker of aggressive breast cancer and promotes neoplastic transformation of breast epithelial cells. Proc Natl Acad Sci USA 100: 11606-11611,2003.

28. Raaphorst FM, Meijer CJ, Fieret E, Blokzijl T, Mommers E, Buerger H, Packeisen J, Sewalt RA, Otte AP and van Diest PJ: Poorly differentiated breast carcinoma is associated with increased expression of the human polycomb group $E Z H 2$ gene. Neoplasia 5: 481-488, 2003.

29. Kunju LP, Cookingham C, Toy KA, Chen W, Sabel MS and Kleer CG: EZH2 and ALDH-1 mark breast epithelium at risk for breast cancer development. Mod Pathol 24: 786-793, 2011.

30. Alford SH, Toy K, Merajver SD and Kleer CG: Increased risk for distant metastasis in patients with familial early-stage breast cancer and high EZH2 expression. Breast Cancer Res Treat 132: 429-437, 2012.

31. Hussein YR, Sood AK, Bandyopadhyay S, Albashiti B, Semaan A, Nahleh Z, Roh J, Han HD, Lopez-Berestein G and Ali-Fehmi R: Clinical and biological relevance of enhancer of zeste homolog 2 in triple-negative breast cancer. Hum Pathol 43: 1638-1644, 2012

32. Dong M, Fan XJ, Chen ZH, Wang TT, Li X, Chen J, Lin Q, Wen JY, Ma XK, Wei L, et al: Aberrant expression of enhancer of zeste homologue 2, correlated with HIF-1 $\alpha$, refines relapse risk and predicts poor outcome for breast cancer. Oncol Rep 32: 1101-1107, 2014.

33. Chang CJ, Yang JY, Xia W, Chen CT, Xie X, Chao CH, Woodward WA, Hsu JM, Hortobagyi GN and Hung MC: EZH2 promotes expansion of breast tumor initiating cells through activation of RAF1- $\beta$-catenin signaling. Cancer Cell 19: 86-100, 2011.

34. Gonzalez ME, Moore HM, Li X, Toy KA, Huang W, Sabel MS, Kidwell KM and Kleer CG: EZH2 expands breast stem cells through activation of NOTCH1 signaling. Proc Natl Acad Sci USA 111: 3098-3103, 2014.

35. Reijm EA, Jansen MP, Ruigrok-Ritstier K, van Staveren IL, Look MP, van Gelder ME, Sieuwerts AM, Sleijfer S, Foekens JA and Berns EM: Decreased expression of EZH2 is associated with upregulation of ER and favorable outcome to tamoxifen in advanced breast cancer. Breast Cancer Res Treat 125: 387-394, 2011.

36. Collett K, Eide GE, Arnes J, Stefansson IM, Eide J, Braaten A, Aas T, Otte AP and Akslen LA: Expression of enhancer of zeste homologue 2 is significantly associated with increased tumor cell proliferation and is a marker of aggressive breast cancer. Clin Cancer Res 12: 1168-1174, 2006.

37. Gonzalez ME, Li X, Toy K, DuPrie M, Ventura AC, Banerjee M, Ljungman M, Merajver SD and Kleer CG: Downregulation of $\mathrm{EZH} 2$ decreases growth of estrogen receptor-negative invasive breast carcinoma and requires BRCA1. Oncogene 28: 843-853, 2009. 